Volume 9, No.4, July - August 2020

International Journal of Advanced Trends in Computer Science and Engineering

Available Online at http://www.warse.org/IJATCSE/static/pdf/file/ijatcse113942020.pdf

https://doi.org/10.30534/ijatcse/2020/113942020

\title{
A Simulation Model and Break-Even Analysis for Improving Painting Robots
}

\author{
Siriya K. ${ }^{1}$, Seksan C. ${ }^{2}$, Fasai W. ${ }^{3}$, Dechathanat T. ${ }^{4}$, Pramot S. ${ }^{5}$, Ismail A.H. ${ }^{6}$ \\ raculty of Engineering, Pathumwan institute of technology, Bangkok, Thailand, nuntiya_777@ hotmail.com \\ ${ }^{2}$ Faculty of Engineering, Pathumwan institute of technology, Bangkok, Thailand, seksan@ @it.ac.th \\ ${ }^{3}$ Faculty of Engineering, Pathumwan institute of technology, Bangkok, Thailand, fasaiw227@ gmail.com \\ ${ }^{4}$ Faculty of Engineering, Pathumwan institute of technology, Bangkok, Thailand, thewan.thong@ gmail.com \\ ${ }^{5}$ Faculty of Engineering, Kasem Bundit University, Bangkok, Thailand, p_srinoi@ hotmail.com \\ ${ }^{6}$ School of Mechatronic Engineering Universiti Malaysia Perlis Perlis, Malaysia, ihalim@ @nimap.edu.my
}

\begin{abstract}
Robotic automation has long been used to replace human workers for tasks having a high degree of risk, such as areas with high heat, hazardous chemical area. The use of robots particularly in industrial painting not only protect human health but also improve the productivity. The robot can work continuously without being tired is an advantage compared to human workers. However, the investment in the robotics project for production is quite high in the initial period. Often the inventor will need to ensure that their investment is worth for which the robotics system to be used at full capacity. In this works, analyzed the break-even points of the production level of ceramic products was conducted after simulated the painting robot layout. To ensure the improvement of the production process to produce satisfactory results before the real hands-on trial, the production process is first simulated with software. FlexSim is a simulation software for simulated, analysis and optimized the painting production process for ceramic factory. In summary, the simulation shows the productivity of a proposed production is more than current production 4.38 times.
\end{abstract}

Key words: Simulation, productivity, motion and time study, break-even point, painting robots

\section{INTRODUCTION}

The industrial robots specifically painting robots were created to keep workers out of "dangerous" jobs as well as increase productivity and maintaining quality. Painting Robots have been invented over 30 years, can be found explicitly in the automotive industries. Painting robots are used by vehicle manufacturers to do detailing work on their cars in a consistent and systematic way. Some of these robots are designed with a robotic arm that moves vertically and horizontally, applying paint jobs on all parts of the car. However, there are many other applications. Ceramic industrial is in group of dusty manufacturing since inside the factory we will find lot of dust from glaze, heat since the factory required an open environment, dirty of clay slip on uniform etc. From these reasons, causing workers leave the factory higher rate than other industries such as semiconductor or electric component manufacturers. Thus, the application of robots in this kind of industry is significantly widely required. In addition, consistent of product quality, continue long time production and controllable operation cost are possible to achieve by using the robots in the production process. However, high investment cost on the robotic application is one of disadvantages. Therefore, the management and engineers must carefully study the information of the project in order to demonstrate the effectiveness of the robots, including the provision of relevant information such as marketing and production capability to the investors, and also for the knowledge of other departments. Initially, the responsible parties for instance the Process Engineers will look on losses that occur in the production process before proposing the robotics solutions. The engineering conventional tools are used for a long time until now for improvement activities [1]. For instance, Lean six-sigma (LSS) [2], [3], Value Stream Mapping (VSM) [4], Total Quality Management (TQM) [5]. While simulation software was interested by engineers such as Arena simulation software [6], [7], and also Delmia [8]. FlexSim is a simulation software using for models and simulates in many kinds of applications such as healthcare, mining etc. The applications are wide, such as in Manufacturing:[9] production, job shop. Material handling: conveyor systems, packaging, warehousing. Logistics and distribution:[10] supply chain design, distribution center workflow, service and storage layout. Others: Oil field or mining processes, networking data flow [11]. Engineering economic tool such as net present value, payback period or break-even analysis [12] are other indicators commonly used to determine profit specially for projects that require a large investment.

The break-even analysis is a useful tool to estimate the return on investment. Its goal is to find the point, in this case in terms of cash and units, where investment costs equates profits. The business is expected to obtain its profitability [13] at some targeted goal point. Managerial decisions require a careful analysis of the costs and profits behavior. In these cases, the break-even linear model is widely used [12]. Both 
revenue and total costs are assumed to be linear in this model, i.e. The constant variables are presented in unit sale price and unit variable cost. The uncertainty is considered implicit. In this work, FlexSim is a software using for modelling and analysing the painting robots of ceramic production process. Throughput, productivity which presented in unit per hour (UPH) and number of workers are three key indicators for comparing between current painting production process and proposed painting production process for this ceramic factory. In order to understand the minimum amount of production that will make no loss in investment, break-even analysis of painting production will be the important indicator of this study.

\section{CURRENT SITUATION}

\subsection{Painting Process Layout}

Currently, standard hanging painting robots as shown in Figure 1 are used in this factory. The Process engineer is responsible for programming to set the path of movement and the painting time for each product.

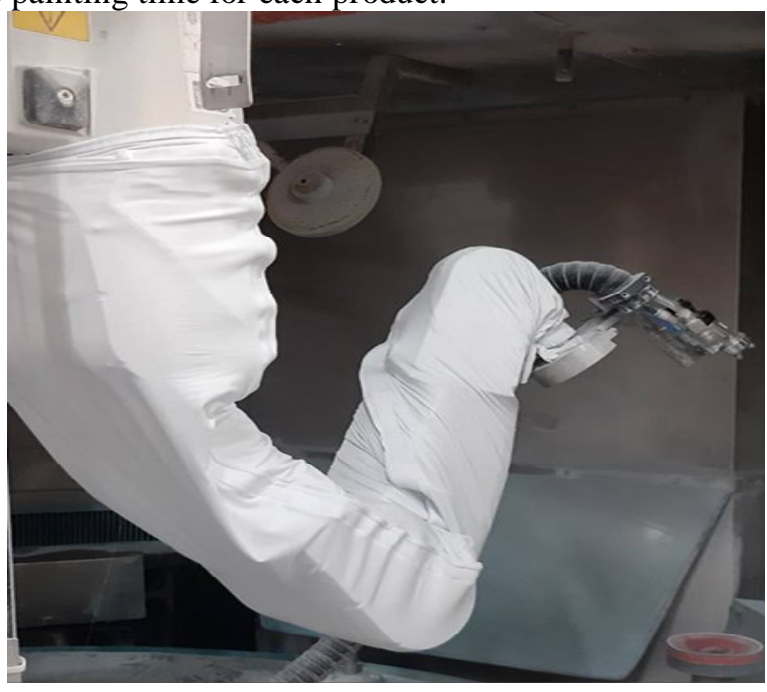

Figure 1: Industrial Painting Robot

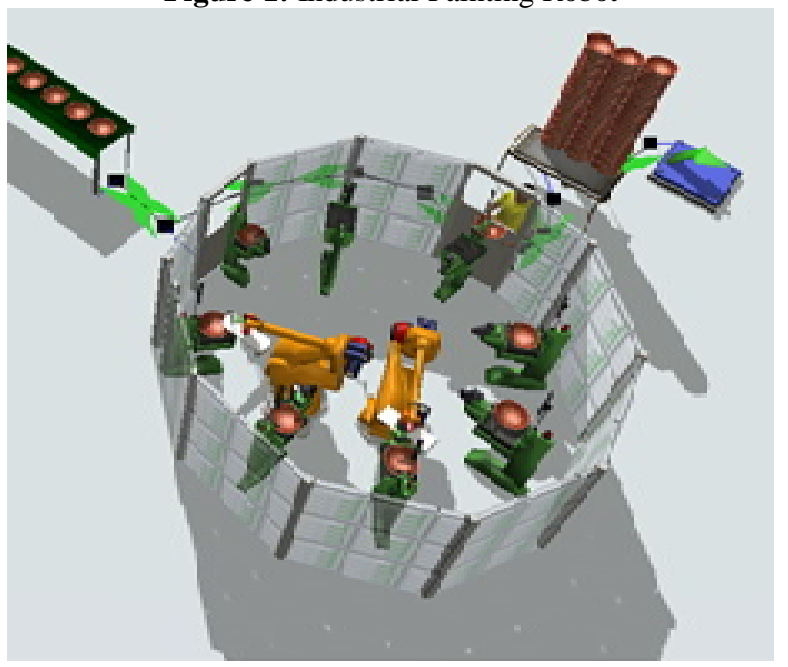

Figure 2: Simulation of the Robots installed in Painting Station
Each painting stations consist of two unit of the painting robots. Each robot is programmed to have a different moving path and painting time. This difference affects the number of the output of each robot (imbalance). The robot installation is depicted in Figure 2. It can be seen that the physical characteristic of vacuum holding systems for workpieces gripping has limit the ability of the robots to paint the product simultaneously on the front and back surface. Therefore, to encounter this problem, the factory decided to use 3 stationary robots which is now able to perform painting in different positions in the expense of extra cost and processing time. The layout of current painting process is shown in Figure 3. Two painting lines are working similar procedures. Painting station-1 is assigned for an exterior painting. There are two robots in this station. The first robot paints exterior path no. 1, while the second robot paints exterior path no. 2. Painting station-2 is assigned for an interior painting. Finally, the $3^{\text {rd }}$ painting station is assigned for painting the special pattern on the product. The two current painting production processes show in Figure 3.

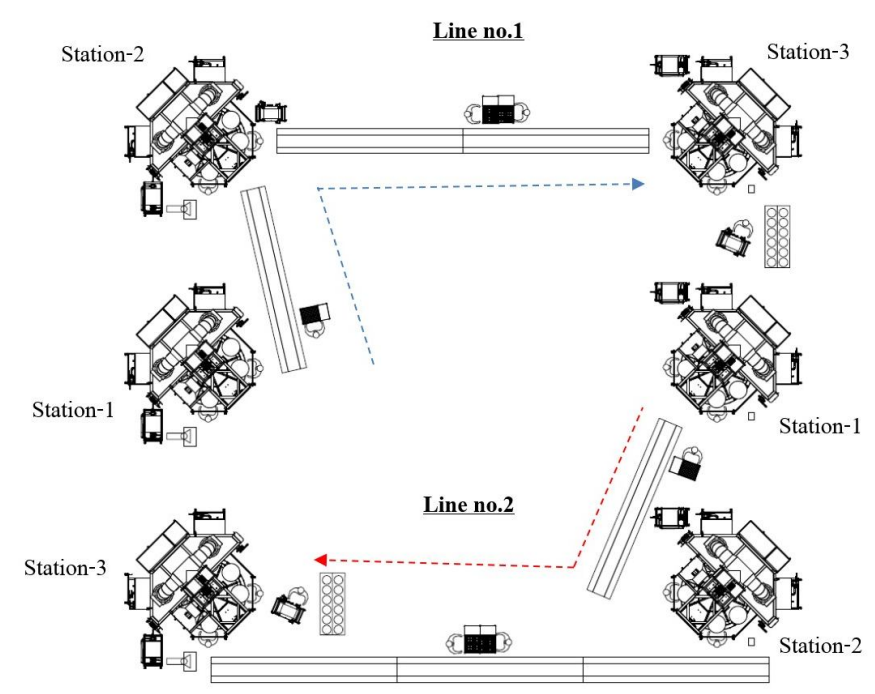

Figure 3: Current Layout of the Painting production process

\subsection{Motion and Time Study}

Figure 4 presented the motion and time study of the current painting process. The total cycle time equal to 481 seconds per unit of ceramic plate product. Workpieces flow through station 1 to station 2, and flow from station 2 to station 3 by conveyor. Total distance of movement is $25.5 \mathrm{~m}$. It can be considered as a very long distance of ceramic painting process for plate. The painting process required a lot of labours although the painting process uses six robots, 11 workers and takes a very long time to produce was questioned about the effectiveness of the investment. Process engineers are assigned to find out the losses in the process and find ways to improve to make the most efficient of painting production. It is hoped that the understanding product characteristics will leads to more efficient production process design. 


\begin{tabular}{|c|c|c|c|c|c|c|}
\hline Location: Painting robot & & & & & Summary & \\
\hline $\mid \begin{array}{|ll|}\text { Activity: } & \text { Plate } \\
\end{array}$ & & & Type & & Present & Proposed \\
\hline Date: $\quad 25-J u l-19$ & & & Oper: & ation & 25 & \\
\hline Analyst : Process enginee & & & Trans & sport & 3 & \\
\hline M ethod and Type: & & & Delay & & 0 & \\
\hline Method: Present Proposed & & & Inspe & ction & 1 & \\
\hline Type: Operator Material & Mach & ine & Stora & & 0 & \\
\hline Yeild : & & & Time & (sec) & 481 & \\
\hline Mat.Margin (\%) : & & & Distan & ce $(\mathrm{m})$ & 25.5 & \\
\hline & & & Cost & & & \\
\hline Event Description & & Symb & & & $\begin{array}{c}\begin{array}{c}\text { Time } \\
\text { (Second) }\end{array} \\
\end{array}$ & $\begin{array}{c}\text { Distance } \\
\text { (m) }\end{array}$ \\
\hline Inspection & D) & D & 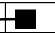 & $\nabla$ & 18 & \\
\hline Cleaning biscuit with water. & $\Rightarrow$ & $\mathrm{D}$ & $\square$ & $\nabla$ & 23 & \\
\hline Cleaning by water and tape on the logo & $\Rightarrow$ & $\mathrm{D}$ & $\square$ & $\nabla$ & 29 & \\
\hline Loading product to station 1 & $\Rightarrow$ & D & $\square$ & $\nabla$ & 13 & 2.5 \\
\hline Move to Robot\#1-1 & $\Rightarrow$ & D & $\square$ & $\nabla$ & 5 & \\
\hline Spray color\#1 position 1 & $\Rightarrow$ & $\mathrm{D}$ & $\square$ & $\nabla$ & 20 & \\
\hline Move to Robot\#1-2 & $\Rightarrow$ & $\mathrm{D}$ & $\square$ & $\nabla$ & 5 & \\
\hline Spray color\#1 position 2 & $\Rightarrow$ & $\mathrm{D}$ & $\square$ & $\nabla$ & 15 & \\
\hline M ove to unloading station & $\Rightarrow$ & $\mathrm{D}$ & $\square$ & $\nabla$ & 5 & \\
\hline Unloading the product to conveyor & $\Rightarrow$ & $\mathrm{D}$ & $\square$ & $\nabla$ & 9 & 2.5 \\
\hline Move to station2 & $\Rightarrow$ & $D$ & $\square$ & $\nabla$ & 18 & 12 \\
\hline Loading product to station2 & $\Rightarrow$ & $\mathrm{D}$ & $\square$ & $\nabla$ & 10 & \\
\hline Move to Robot\#2-1 & $\Rightarrow$ & D & $\square$ & $\nabla$ & 5 & \\
\hline Spray color\#2 position 1 & $\Rightarrow$ & $D$ & $\square$ & $\nabla$ & 23 & \\
\hline M ove to Robot\#2-2 & $\Rightarrow$ & $\mathrm{D}$ & $\square$ & $\nabla$ & 5 & \\
\hline Spray color\#2 position 2 & $\Rightarrow$ & $\mathrm{D}$ & $\square$ & $\nabla$ & 21 & \\
\hline M ove to unloading station & $\Rightarrow$ & $D$ & $\square$ & $\nabla$ & 5 & \\
\hline Unloading the product to conveyor & $\Rightarrow$ & $\mathrm{D}$ & $\square$ & $\nabla$ & 9 & 2.5 \\
\hline M ove to station3 & $\Rightarrow$ & $D$ & $\square$ & $\nabla$ & 18 & 3 \\
\hline M ove to Finish by conveyor & 3 & D & $\square$ & $\nabla$ & 18 & 3 \\
\hline Finishing & $\Rightarrow$ & $\mathrm{D}$ & $\square$ & $\nabla$ & 94 & \\
\hline Loading product to station 3 & $\Rightarrow$ & $D$ & $\square$ & $\nabla$ & 10 & \\
\hline Move to Robot\#3-1 & $\Rightarrow$ & D & $\square$ & $\nabla$ & 5 & \\
\hline Spray color\#3 position 1 & $\Rightarrow$ & D & $\square$ & $\nabla$ & 23 & \\
\hline Move to Robot\#3-2 & $\Rightarrow$ & $\mathrm{D}$ & $\square$ & $\nabla$ & 5 & \\
\hline Spray color\#3 position 2 & $\Rightarrow$ & $D$ & $\square$ & $\nabla$ & 21 & \\
\hline M ove to unloading station & $\Rightarrow$ & $\mathrm{D}$ & $\square$ & $\nabla$ & 5 & \\
\hline Unloading product and Polishing & $\Rightarrow$ & $\mathrm{D}$ & $\square$ & $\nabla$ & 21 & \\
\hline Cleaning transfer product to car rack & $\Rightarrow$ & D & $\square$ & $\nabla$ & 28 & \\
\hline
\end{tabular}

Figure 4: Motion and Time Study of Current Painting Production 2.3 Productivity

Figure 5 presented the imbalance output of current painting production process. The output of 6.5 working hours is 466 pieces. The productivity at each hour at painting production line no. 1 is 6.52 pieces per man per hour only.

In order to increase the painting robot efficiency, the Process Engineer is given a task to design a new painting production process which will reduce the losses as occurred in the current painting processes as described previously.

Simulation by FlexSim was used to analyse the output that will be get from the proposed process. Then the break-even point analysis used to find the best solution for selecting the improvement project.

\section{METHODOLOGY}

\subsection{Break-Even Point}

The break-even point is the point where the business's sales have generated enough income to cover total of fixed costs and expenses.

$$
\text { Contribution per unit }=P-V C
$$

On the other hand, the Break Even Point in Quantity (BEP) can be computed by

$$
B E P=\frac{F C}{P-V C}
$$

Where $F C$ is the fixed cost, $P$ is unit sale price and $V C$ is unit variable cost.

The break-even point identifies the total amount of benefit the painting production process needs before profit can be earned. When analysed closely, the break-even analysis also helps the factory to identify excessive fixed costs. Since the break-even point is directly related to the fixed costs, then reducing and controlling these costs aids the factory in achieving a lower break-even point, which mean the profit can be accessed quickly.

\subsection{Production Process and Layout Design}

As described previously, the limitations of vacuum holding system causes system inefficiency although the colour of frontal and back are the same. The workpiece is firstly sprayed on the top surface at the first painting station, and then fetch to second painting station to spray the bottom surface. An automated spray booth and vacuum holding system were newly designed to solve this matter. Interior and exterior painting at the same time and same station was good benefit of the newly design. Figure 6 shows the new painting station production process layout. The objective to employ the robot for the proposed layout is to get the highest efficient. It should be mentioned that the painting robots are using for painting the special colour pattern only.

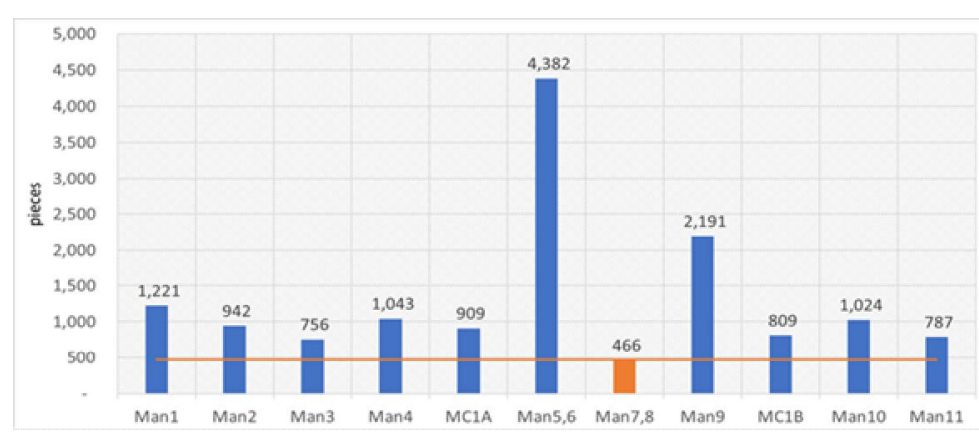

Figure 5: Output of Current Painting Production Process 


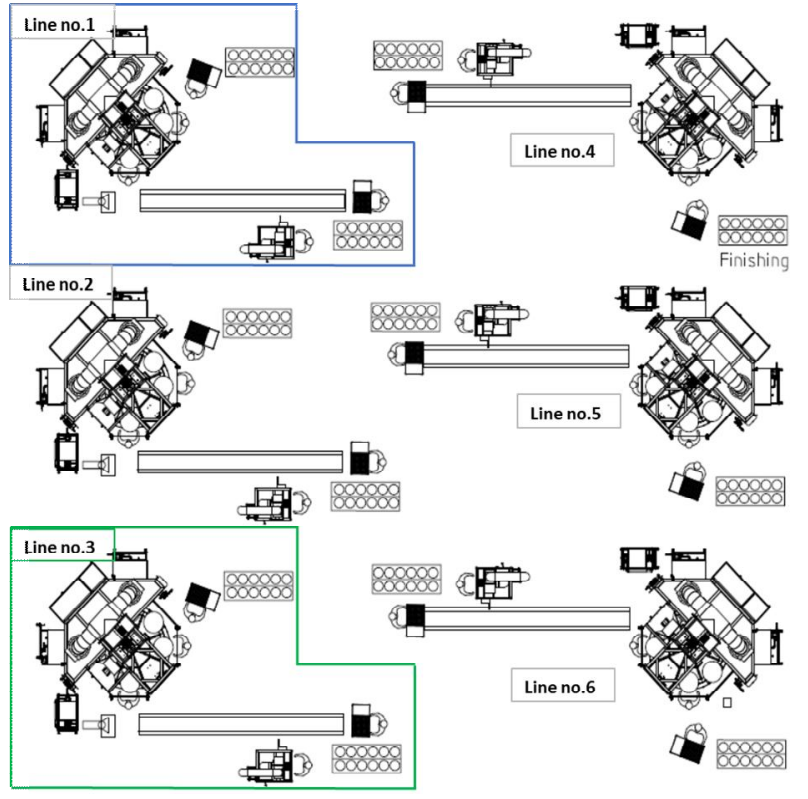

Figure 6: Proposed Painting Production Process

\begin{tabular}{|c|c|c|c|c|c|c|c|}
\hline Location: Painting robot & & & & & & Summary & \\
\hline Activity: plate & & & & Type & & Present & Proposed \\
\hline Date: $\quad 29$-Aug-19 & & & & Opera & tion & & 5 \\
\hline Analyst : Process en & & & & Trans & Dort & & 1 \\
\hline Method and Type: & & & & Delay & & & 0 \\
\hline Method: Present Proposed & & & & Inspe & tion & & 1 \\
\hline Type: Operator Material & & Mach & ine & Stora & & & 0 \\
\hline Yeild: & & & & Time & sec) & & 103 \\
\hline Mat.Margin (\%) : & & & & Distan & ce $(\mathrm{m})$ & & \\
\hline & & & & Cost & & & \\
\hline Event Description & & & Symbo & & & $\begin{array}{c}\text { Time } \\
\text { (Second) }\end{array}$ & Distance $(\mathrm{m})$ \\
\hline Inspection and Cleaning biscuit with water & & Б) & $\mathrm{B}$ & $\theta$ & $\nabla$ & 21 & \\
\hline Loading product to auto spray booth & & $\Rightarrow$ & D & $\square$ & $\nabla$ & 9 & \\
\hline Auto spray booths & & $\Rightarrow$ & $\mathrm{D}$ & $\square$ & $\nabla$ & 10 & \\
\hline Loading product to station 1 & & $\Rightarrow$ & $\mathrm{D}$ & $\square$ & $\nabla$ & 3 & \\
\hline Move to Robot\#1-1 & & $\Rightarrow$ & $\mathrm{D}$ & $\square$ & $\nabla$ & 37 & 6 \\
\hline Spray color\#1 position 1 & & $\Rightarrow$ & D & $\square$ & $\nabla$ & 6 & \\
\hline Move to Robot\#1-2 & & $\Rightarrow$ & $\mathrm{D}$ & $\square$ & $\bar{\nabla}$ & 3 & \\
\hline Spray color\#1 position 2 & & $\Rightarrow$ & $\mathrm{D}$ & $\square$ & $\nabla$ & 18 & \\
\hline Move to unloading station & & $\Rightarrow$ & $\mathrm{D}$ & $\square$ & $\nabla$ & 3 & \\
\hline Unloading product and Polishing & & $\Rightarrow$ & $\mathrm{D}$ & $\square$ & $\nabla$ & 4 & \\
\hline CC and Transfer product to car rack & & $\Rightarrow$ & $\mathrm{D}$ & $\square$ & $\nabla$ & 16 & 3 \\
\hline
\end{tabular}

Figure 7: Motion and Time Study of Proposed Layout for Processes for Single Colour Plate Single Colour Plate

\subsection{Motion and Time Study}

The motion and processing time of the newly proposed painting production process layout and process flow chart is analysed specifically for single-coloured ceramic plate. The result of this analysis is shown in Figure 7 involved 5 workers, yielding the total cycle time of the proposed painting process for single colour plate is 103 seconds per one piece. The process's cycle time is reduced to $78.59 \%$ compared to the current practice, and the distance of movement is reduced to 9 meters, or $64.71 \%$ reduction from current operation. The results of the new painting production process design by experienced engineers by using traditional process analysis tools have a significant effect on the efficiency of the painting process.
Benefit of the proposed painting production process are, reduction of cycle time, distance of movement and reducing the number of workers. These results, lead to process simulation by FlexSim software. The simulation shall compare between current painting process and proposed painting process for single colour plate.

\subsection{Simulation}

Two painting production processes were simulated in this study, which are the current painting process shown in Figure 8 , and the proposed painting process for single colour plate shown in Figure 9. The parameters of each variables are based on the motion and time study as described in Figure 4 and Figure 7.

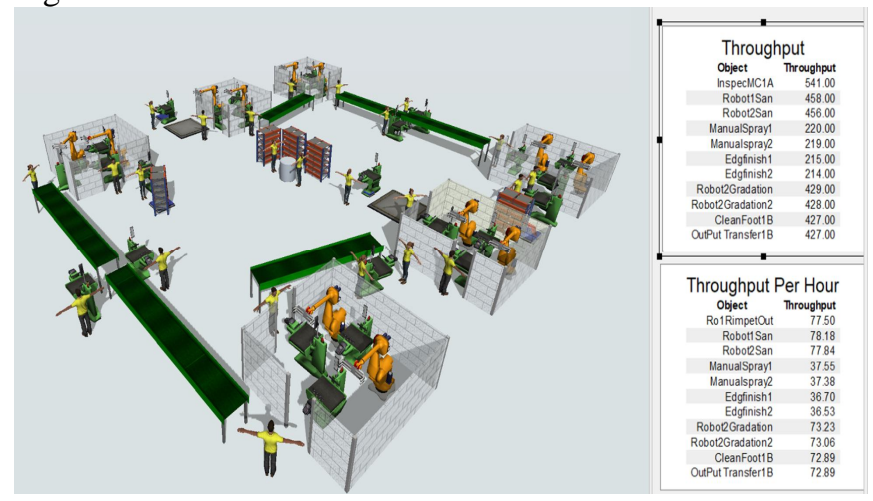

Figure 8: Simulation of Current Painting Production Process

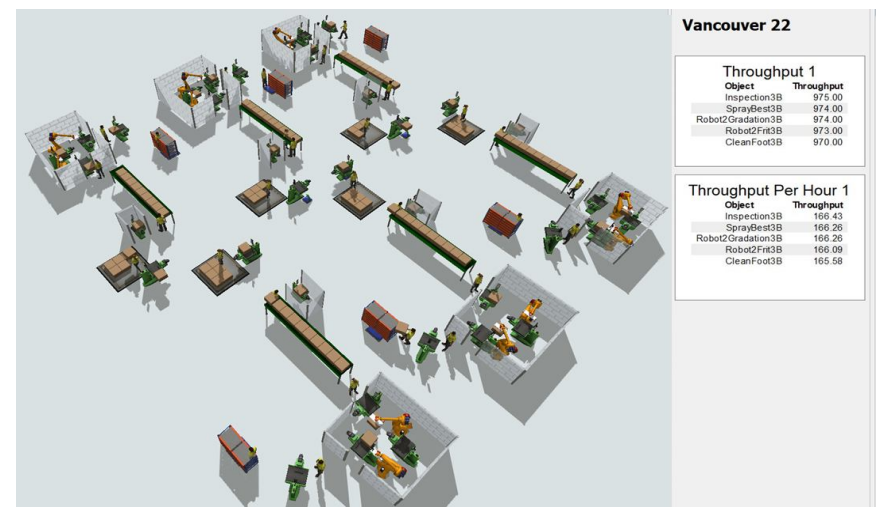

Figure 9: Simulation of Proposed Painting Production Process

As depicted in Figure 9, the production lines had been shortened, resulting in shorter operation time and shorter moving distance. In addition, it can also help the production supervisor to closely supervised the workers, affecting the production with better quality. The position of the workers has been rearranged as shown in Figure 9. Each worker will work with different duties and different operation time as shown by the motion and time study in Figure 7 which are,

Worker-1: Inspect and cleaning raw materials. Worker-2: Operate the automated spray booth. Worker-3: Load workpiece to painting robots. 
Siriya K et al., International Journal of Advanced Trends in Computer Science and Engineering, 9(4), July - August 2020,4977 - 4983

Worker-4: Unload workpiece from painting robots and polishing.

Worker-5: Collected a finished product and keep on the cart.

\section{RESULTS AND ANALYSIS}

\subsection{Simulation Results}

Table 1: Current Painting Production Processes Results

\begin{tabular}{|l|c|}
\hline \multicolumn{1}{|c|}{ Indicator } & Result \\
\hline Daily throughput & 2,796 unit \\
\hline Total number of workers & $66 \mathrm{persons}$ \\
\hline Productivity & $6.52 \mathrm{unit} / \mathrm{man} / \mathrm{hour}$ \\
\hline
\end{tabular}

Table 2: Proposed Painting Production Processes Results of Single Colour Ceramic Plate

\begin{tabular}{|l|c|}
\hline \multicolumn{1}{|c|}{ Indicator } & Result \\
\hline Daily throughput & 16,740 unit \\
\hline Total number of workers & 90 persons \\
\hline Productivity & $28.61 \mathrm{unit} / \mathrm{man} /$ hour \\
\hline
\end{tabular}

\section{A. Number of workers}

Current production process flow chart is shown in Figure 3 the number of current production workers is 11 workers/shift/line or total workers will be 66 workers per day. While 5 workers/shift/line is employed for the proposed painting production process or total required 90 workers per day.

This issue is the shortcoming of the proposed system. Although the number of workers increase a bit, the processing time has significantly reduced. For the single colour plate painting production process, throughput has increased to almost 6 times from the present while the number of workers has just increase 1.36 times. It's a balance bargain.

\section{B. Productivity}

Relationship between number of workers and output is presented by productivity level. Table 1 shows the productivity of current painting production process equal to 6.52 UPH. While productivity of the proposed painting production process shows in table 2 is $28.61 \mathrm{UPH}$.

\section{Throughput}

The mostly utilization of the painting robots, the factory must use the robots 24 hours. Table 1 shows the output of current painting production process is 2,796 pieces/day. Simulation result of the proposed painting production process shows in table 2 the output achieved to 16,740 pieces/day.

\subsection{Results of Break-Even Analysis}

\section{A. Conditions}

- 1.8 USD per man-hr was considered from direct labour to be presented as Variable cost.

- 31.25 USD/hour/painting station was Fixed cost.
- The revenue of single colour plate is 1.20 USD per unit.

From the revenues and costs data above, by input the value into (2) be able to know the break-even point of the painting production process for single colour plate of this factory.

\section{B. Break-Even Analysis}

Determined the value of each variables, found

- $F C$ is fixed cost of proposed for single colour painting production process calculated depreciation at 10 years, working hours 19.5 hours per day and 26 working day a month. The fixed cost is,

$$
F C=31.25 \times 6 \times 19.5 \times 26=95,062.50 \mathrm{USD} / \mathrm{month}
$$

- $\quad V C l$ is variable cost of current painting production process. Total worker is 66 persons for 2 painting production processes with 3 shifts operation pattern.

$$
V C 1=(1.80 \times 66) / 2,796=1.02 \mathrm{USD} / \text { piece. }
$$

- $\quad V C 2$ is variable cost of proposed painting production process. Total worker is 90 persons for 2 painting production processes with 3 shifts operation pattern.

$$
V C 2=(1.80 \times 90) / 16,740=0.23 \mathrm{USD} / \text { piece. }
$$

From (2) and information we have,

BEP current $=3,656 /(1.20-1.02)=20,283$ pieces per day

BEP proposed $=3,656 /(1.20-0.23)=3,778$ pieces per day

The calculation results presented that BEP of the current painting production process is more than BEP of the proposed painting production process equal to 5.37 times. Hence it can be assumed that the opportunities that the proposed painting production processes can generate profits at 5.37 times faster than current painting production processes.

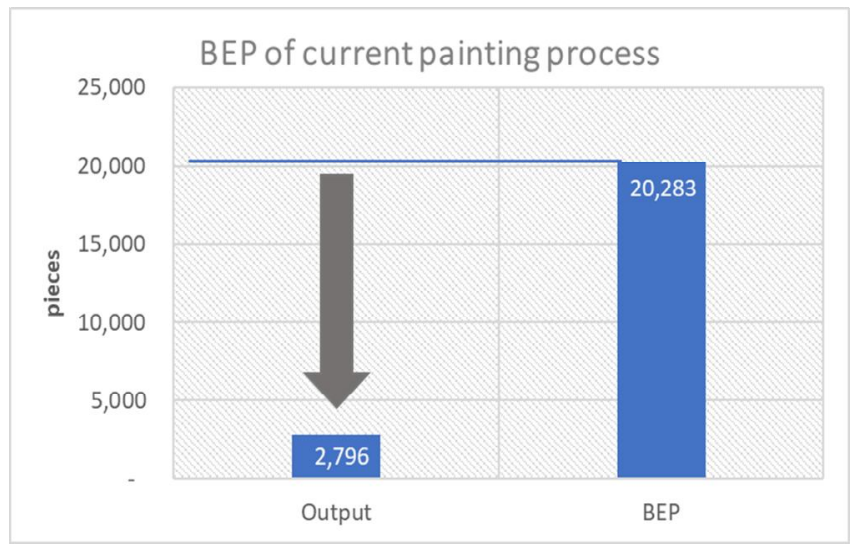

Figure 10: Comparison of Output and BEP in Unit of Quantity of Current Painting Process 
Current painting process presented in Figure 10 the break-even point equal to 20,283 pieces but current output of this process is only 2,796 pieces per day. Therefore, it is not possible to be able to profit from production with the current painting production processes.

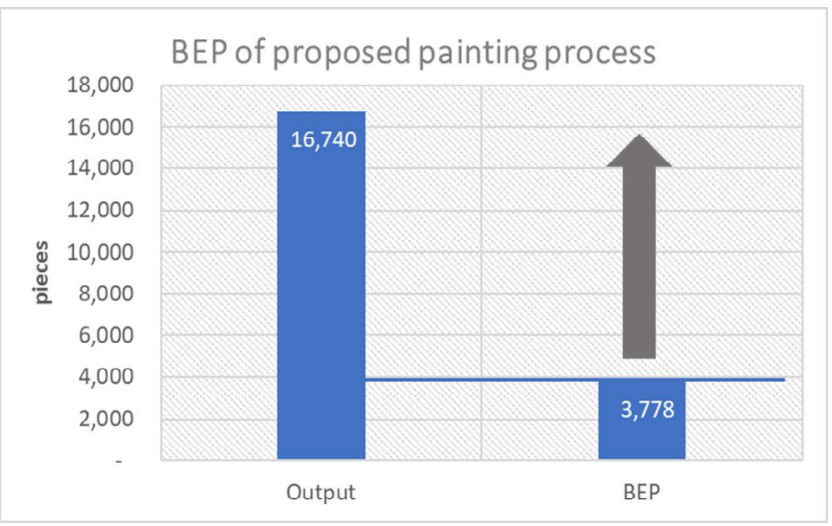

Figure 11: Comparison of Output and BEP in Unit of Quantity of Proposed Painting Process

While proposed painting process presented in Figure 11 the break-even point is 3,778 pieces and output equal to 16,740 pieces per day. Therefore, the proposed production process has the potential to be able to make profit easily.

\section{CONCLUSION}

The continuous improvement in factory plant is a must-job to do as it could increase production efficiency and reducing the loss while maximizing the profit, especially when dealing with costly operation of machineries such as the painting robots. It must be used to its fully potential and maximum capacity.

Process analysis using traditional engineering tools such as motion and time study can provide better analysis results when integrated with simulation software such as FlexSim.

The analysis of break-even point is used to help decide the project that should be used to increase the productivity and efficiency of the production process.

To summarise, the methods applied in this work should be able to cater some of efficiency problems where it is found that the proposed painting process can generate profits 5.37 times faster than the current painting production, thus benefits both parties i.e. the investor and the workers.

\section{ACKNOWLEDGEMENT}

This works is done thanks to suggestions and recommendations from advisory boards consisting of teachers and staffs at the ceramic factory, who participant until the end of project completion.

\section{REFERENCES}

1. E. Westkämper. Digital Manufacturing in the Global Era, Digital Enterprise Technology: Perspectives and Future Challenges (ed. Cunha, P.F., Maropoulos, P.G.), Springer, 2007.

2. Burgess, N., Radnor, Z. and Davies, R. Taxonomy of Lean in healthcare: A framework of Evaluating Activity and Impact, Proceedings of EurOMA conference 2009, pp.1 - 10.

3. Fairul Anwar A B, Mohd Amran M D, Mohamad Ikbar A W, Khairanum S, Ishamuddin M and Mazlan A. Lean Six Sigma Implementation on Reducing Incoming Processes Time in QA Department at Reckitt Benckiser Sdn Bhd, International Journal of Advanced Trends in Computer Science and Engineering, Volume 9, No.1.1, 2020, pp.252-258. https://doi.org/10.30534/ijatcse/2020/4591.12020

4. Anand Sasikumar and Kundan Kumar. Value Stream Mapping in a Manufacturing Company, IRACST International Journal of Commerce, Business and Management (IJCBM), ISSN: 2319-2828, Vol. 2, No.2, April 2013, pp.136 - 145.

5. Mohd Amran M D, Mohamad Ikbar A W, Fairul Anwar $\mathrm{AB}$ and Khairanum $\mathrm{S}$. The Implementation Effectiveness of Quality Tools and Techniques, International Journal of Advanced Trends in Computer Science and Engineering, Volume 9, No.1.1, 2020, pp.191-198.

https://doi.org/10.30534/ijatcse/2020/3491.12020

6. Rahman C. M. and Sabuj S. U. PROCESS FLOW IMPROVEMENT PROPOSAL OF A BATCH MANUFACTURING SYSTEM USING ARENA SIMULATION MODELING, Review of General Management, 21(1), 2015, pp.63-77.

7. John B. and E. Jenson Joseph. Analysis and simulation of factory layout using ARENA, International Journal of Scientific and Research Publications, 3(2), 2013, pp.1 -8 .

8. Elena-Iuliana Gingu and Miron Zapciu. Improving layout and workload of manufacturing system using Delmia Quest simulation and inventory approach, International Journal of Innovative Research in Advanced Engineering (IJIRAE), Volume 1, Issue 6, July 2014, pp.52 - 61.

9. Erol Gelenbe and Hatim Guennouni, FlexSim: A flexible manufacturing system simulator, European Journal of Operational Research, Volume 53, Issue 2, July 25, 1991, pp.149 - 165 .

10. U.Sravan Kumar and Shivraj Yeole. Productivity Improvement through Optimization of Layout using Flexsim Simulation Software, 5th National Conference on Advances in Mechanical Engineering, At Vasavi College of Engineering, Hyderabad, Volume: 01, May 2015, pp.64- 67.

11. Marta Rostkowska. SIMULATION OF PRODUCTION LINES IN THE EDUCATION OF ENGINEERS: HOW TO CHOOSE THE RIGHT 
SOFTWARE, Management and Production Engineering Review, Volume 5, No.4, December 2014, pp.53-65.

https://doi.org/10.2478/mper-2014-0036

12. Murdock J., Phillips C. and Beane R. Break-even analysis of Medicaid vs. fee for service in orthodontic practice, American Journal of Orthodontics and Dentofacial orthopedics, 137 (3), 2010 pp.334 - 339. https://doi.org/10.1016/j.ajodo.2008.08.024

13. Leon, V.J. Operations research in manufacturing, Manufacturing Engineering Handbook, New York: McGraw-Hill, 2004, pp.15.1-15.18. 